\title{
Posttraumatic hip bulging mimicking an abscess in a patient with hip prosthesis: the role of ultrasonography
}

\author{
Laura Damian', Siao-Pin Simon"1,4, Ioana Felea1, Mihaela Coman², Daniela Fodor ${ }^{3,4}$, \\ Cezara Voica ${ }^{5}$
}

${ }^{1}$ Rheumatology Department, Emergency County Hospital, ${ }^{2}$ Radiology Department, Emergency County Hospital, ${ }^{3} 2^{\text {nd }}$ Internal Med Department, Emergency Clinical County Hospital, "'Iuliu Hatieganu" University of Medicine Cluj-Napoca, ${ }^{5}$ National Institute for Research and Development of Isotopic and Molecular Technologies, Cluj-Napoca, Romania

\begin{abstract}
A 48-yr old female patient, with stage 4 rheumatoid arthritis, who had undergone multiple joint prostheses including four arthroplasties of the left hip, presented for a sudden-onset large bulge on the left thigh, after a minor local injury. Orthopedic examination and radiography excluded fractures. Ultrasonography revealed a large mixed hypo- and hyperechoic collection, with no Doppler signal, but with comet tail artifacts. Repeated cultures from the collection were negative. Fluid analysis revealed increased quantities of titanium and cobalt. The sudden-onset deformity and fluid collection were in favor of a shear lesion (Morel-Lavallée). The new collection communicated with a previously asymptomatic periprosthetic aseptic abscess, mimicking an infection. To our knowledge, Morel-Lavallée shear lesions have not been described in patients with hip prostheses. Their presence may add to the difficulties of ruling out silent infections in such patients. Ultrasonography is a very effective method for the diagnosis and follow-up of collections in this setting.

Keywords: hip prosthesis; aseptic loosening; shear lesion; metallosis; ultrasonography
\end{abstract}

\section{Introduction}

Post-traumatic hip lesions in patients with hip prosthesis may elicit several differential diagnoses: fracture, hematoma, prosthesis displacement and loosening, infections, aseptic abscesses or pseudotumors due to wearinduced debris [1]. Upper thigh bulging may also be due to a Morel-Lavallée or shear lesion (MLL), a closed degloving injury over the great femoral trochanter, with separation of subcutaneous fat from the underlying fascia [2]. We present the role of ultrasonography (US) in

Received 10.09.2018 Accepted 29.10.2018

Med Ultrason

2019, Vol. 21, No 2, 191-193

Corresponding author: Siao-pin Simon

Rheumatology Department

2-4 Clinicilor Street, Cod 400006

Cluj-Napoca, Romania

Phone: +40745665119

E-mail: siao_2003@yahoo.com diagnosing an upper thigh collection in a patient with a hip prosthesis.

\section{Case report}

A 49-yr old female patient, with stage 4 rheumatoid arthritis underwent multiple joints prosthetic arthroplasties. The $4^{\text {th }}$ total revision arthroplasty of the left hip was performed 4 years previously for aseptic loosening, with a hybrid endoprosthesis with non-cemented tail. The patient presented for a painful, fluctuating bulging on the upper lateral third of the left thigh, after a minor local injury (fig 1a). Hip radiography showed bilateral total hip arthroplasty, with loosening and acetabular displacement on the left side (fig $1 b$ ).

Ultrasonography (US) (Esaote ultrasound machine with a 13-18 MHz linear probe) revealed a large mixed hypo- and hyperechoic collection, with minimal Doppler signal, but with shining artifacts with a comet tail (fig $1 \mathrm{c}-\mathrm{f})$. As a sinus tract was noted at the collection margin, 
infection was strongly suspected and current biologic therapy for rheumatoid arthritis was withdrawn.

Laboratory showed normal leukocyte count (8000/ $\mathrm{mm}^{3}$, with $65 \%$ polymorphonuclear neutrophils), normal erythrocytes sedimentation rate, elevated C-reactive protein $(24 \mathrm{mg} / \mathrm{L}$, range $0-6 \mathrm{mg} / \mathrm{L})$ and negative procalcitonin $(<0.5 \mathrm{ng} / \mathrm{mL})$. The collection draining under US guidance revealed a serocitrin fluid, with no leukocytes or bacterial growth, even on special environments, $M y$ cobacteria included (fig 1g). Antibiotics (clindamycin, ciprofloxacin) were empirically given with no local change. The multi-elemental metal assessment in the synovial fluid and blood, performed using inductively coupled-plasma mass spectrometry (ICP-MS), with a Perkin-Elmer Elan DRC-e ICP-MS, revealed increased quantities of titanium and cobalt in the fluid, with normal blood titers (Table I). The lymphocyte transformation test to metals ( $\mathrm{Au}, \mathrm{Ni}, \mathrm{Pd}, \mathrm{Cr}, \mathrm{Co}, \mathrm{Mo}, \mathrm{Ti}, \mathrm{Pt}, \mathrm{Al}, \mathrm{Cd}, \mathrm{Hg}, \mathrm{Cu}$, $\mathrm{Ag}, \mathrm{Zn}, \mathrm{Hg}$ ) was negative. Contrast-enhanced pelvic CT scan (Siemens Somatom Definition AS 20-slice CT scanner, SCJU Cluj-Napoca) performed during follow-up revealed an encapsulated collection in the left hip subcutaneous tissue extending through the underlying fascial planes to the periprosthetic soft tissue (fig $1 \mathrm{~g}$ ).
Table I. The multi-elemental assessment using the ICP-MS technique in plasma

\begin{tabular}{llll}
\hline & \multicolumn{3}{c}{ Metal concentrations [ug/L] } \\
Metal & Studies & Blood & Synovial fluid \\
\hline $\mathrm{Ti}$ & Our study & 3.7 & 36.3 \\
& {$[13]$} & $2.7-17$ & 13 \\
$\mathrm{Cr}$ & Our study & 0.9 & 0.2 \\
& {$[13]$} & $2-4$ & 3 \\
$\mathrm{Co}$ & Our study & $<0.1$ & 14.4 \\
& {$[13]$} & $0.1-1.2$ & 5 \\
$\mathrm{Mo}$ & Our study & 1.3 & $<0.5$ \\
& {$[13]$} & $0.5-1.8$ & 21 \\
\hline
\end{tabular}

The sudden onset of the deformity and fluid collection were suspected to be a shear lesion (MLL), communicating with a periprosthetic sterile abscess. Revision arthroplasty was not performed due to marked femoral osteoporosis. Biologic therapy was restarted for rheumatoid arthritis, along with bisphosphonates.

\section{Discussions}

MLL is a rare and under-diagnosed cause of peritrochanterian bulging. MLL occurs after a low-velocity

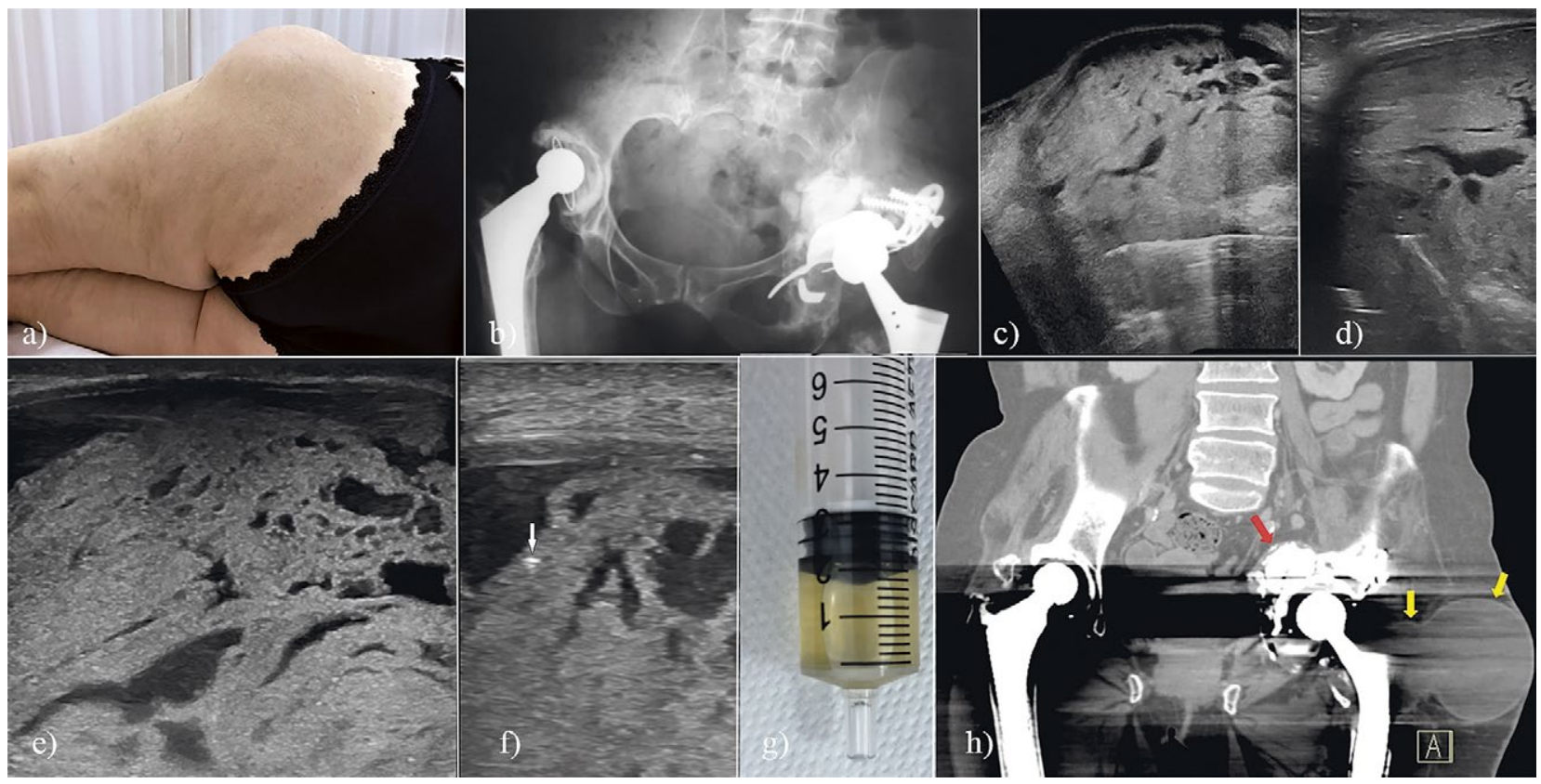

Fig 1. a) clinical aspect of the left hip pseudotumor; b) antero-posterior pelvic radiography: bilateral total hip arthroplasty; intrapelvic protrusion of the cement mantle with loosening and displacement of the inferior part of the acetabular component on the left side; c) and d) US panoramic image with fluid collection, pseudoparenchymal organization and metal reverberation; d) panoramic US view; e) and f) detailed aspect of collection and parenchymal component, with comet tail artifacts (arrow); g) macroscopic aspect of the apirated fluid; $h$ ) contrast-enhanced pelvic CT scan, coronal plane: intrapelvic migration of cement and acetabular prosthetic components of the left total hip arthroplasty (red arrow) and a hypodense unenhanced collection in the left hip subcutaneous tissue extending through the underlying fascial planes to the periprosthetic soft tissue (yellow arrows) 
injury over the great trochanter, resulting in the separation of subcutaneous fat from the underlying fascia. The resulting cavity and chronic fluid collection are best assessed by magnetic resonance imaging (MRI) or US, which may see a thickened capsule surrounding a hyperechoic or an anechoic area [2].

In the soft tissues the adverse reactions to prosthetic debris, also called inflammatory pseudotumors, aseptic lymphocytic vasculitis-associated lesions, metallosis, pseudobursae, etc, range from small asymptomatic cysts to large solid or mixed soft tissue masses $[1,3,4]$. Metal particles may activate type IV delayed hypersensitivity reactions or may disseminate [5]. The lesions also occur in polyethylene and surface replacement arthroplasties and even in well-positioned implants [4]. Irregular walls, sinus tracts or bone destruction may suggest infection [1].

Periprosthetic pseudotumors are best assessed by MRI with metal artefact reduction sequencing, but older metal devices limit its use [3]. CT scans are accurate in describing positioning and other complications, but limited in soft tissue characterization $[3,4]$.

US detects solid or cystic pseudotumors in asymptomatic patients with prostheses, with sensitivity and specificity comparable to MRI $[4,6,7]$. A low-frequency probe is used for the gray-scale imaging of the anterior, lateral and posterior aspects of the hip [8]. Pseudotumors may be seen as simple fluid-filled cysts, as solid masses or as complex cystic fluid-filled masses with thick walls, generally without a Doppler signal $[6,8]$. Abnormally straight or convex iliofemural ligament upon US assessment may early suggest pseudotumor development [9]. Metal particles usually produce comet tail artifacts, also caused by small calcific, crystalline, plastic objects or air, sometimes indicating the presence of abscesses or necrosis [10]. Local reactions, mainly sinus tracts and laboratory tests may mimic peri-prosthetic joint infections $[11,12]$. In our patient, the sinus tract was due to a communication between a previous, asymptomatic periprosthetic pseudotumor and the MLL, as suggested by the metal occurrence in the latter. Metal measurements in pseudotumors have limited utility for predicting reactions [6].

To our knowledge, MLL shear lesions have not been described in patients with hip prostheses. Their presence may add to the difficulties of ruling out silent infections in patients with aseptic prosthetic complications. US is an important technique for the diagnosis and treatment of the periarticular fluid collections, shear lesions and also for serially monitoring the aseptic prosthetic complications.

Acknowledgements: Drs. Claudiu Tănăselia, Oana Cadar, Maria-Magdalena Tamas, Prof. Dr Simona Rednic for the assistance in the following up of the patient.

\section{References}

1. Keogh CF, Munk PL, Gee R, Chan LP, Marchinkow LO. Imaging of the painful hip arthroplasty. AJR Am J Roentgenol 2003;180:115-120.

2. Miller J, Dagget J, Ambay R, Payne WG. Morel-Lavallee lesion. Eplasty 2014;14:ic12.

3. Davies DL, Morrison JJ. Hip arthroplasty pseudotumors: pathogenesis, imaging, and clinical decision making. J Clin Imaging Sci 2016;6:17.

4. Nam D, Barrack RL, Potter HG. What are the advantages and disadvantages of imaging modalities to diagnose wear-related corrosion problems? Clin Orthop Relat Res 2014;472:3665-3673.

5. Urban RM, Jacobs JJ, Tomlinson MJ, Gavrilovic J, Black J, Peoc'h M. Dissemination of wear particles to the liver, spleen, and abdominal lymph nodes of patients with hip or knee replacement. J Bone Joint Surg Am 2000;82:457-476.

6. Williams DH, Greidanus NV, Masri BA, Duncan CP, Garbuz DS. Prevalence of pseudotumor in asymptomatic patients after metal-on-metal hip arthroplasty. J Bone Joint Surg Am 2011;93:2164-2171.

7. Nishii T, Sakai T, Takao M, Yoshikawa H, Sugano N.: Ultrasound screening of periarticular soft tissue abnormality around metal-on-metal bearings. J Arthroplasty 2012;27:895-900.

8. Lainiala O, Elo P, Reito A, Pajamäki J, Puolakka T, Eskelinen A. Good sensitivity and specificity of ultrasound for detecting pseudotumors in 83 failed metal-on-metal hip replacements. Acta Orthop 2015;86:339-344.

9. Robinson DJ, Lee S, Marks P, Schnmeider ME. Ultrasound screening for adverse local tissue reaction after hip arthroplasty. Ultrasound Med Biol 2017;43:1549-1556.

10. Taljanovic MS, Melville DM, Scalcione LR, Gimber LH, Lorenz EJ, Witte RS. Artifacts in musculoskeletal ultrasonography. Semin Musculoskel Radiol 2014;18:3-11.

11. Yi PH, Cross MB, Moric M, et al. Do serologic and synovial tests help diagnose infection in revision hip arthroplasty with metal-on-metal bearings or corrosion? Clin Orthop Relat Res 2015;473:498-505.

12. Parvizi J, Gehrke T; International Consensus Group on Periprosthetic Joint Infection. Definition of periprosthetic joint infection. J Arthroplasty 2014;29:1331.

13. Hallab NJ, Mikecz C, Vermes C, Skipor A, Jacobs JJ. Orthopedic implant related metal toxicity in terms of human lymphocyte reactivity to metal-protein complexes produced from cobalt-base and titanium-base implant alloy degradation. Mol Cell Biochem 2001;222:127-136. 